\title{
Neutral Zone: Concept and Technique Application for Managing Severely Resorbed Mandibular Ridges - A Case Report
}

\author{
Ainy F. Nuriyanto, Rostiny, Bambang Agustono
}

Department of Prosthodontic Faculty of Dental Medicine Airlangga University, Surabaya, Indonesia

Email: ainy.fitri@gmail.com

Received: October 22, 2021; Accepted: February 3, 2022; Published on line: February 5, 2022

\begin{abstract}
Full dental prosthesis rehabilitation on flat mandibular ridge has been a difficult case for clinicians for a long time. A huge resorption of mandibular ridge results in inadequate retention, and tounge muscle pressure, as well as lip and cheek muscles, causing a decrease in denture's stability and retention. Neutral zone is a potential area or position where lips and cheek on one side, and tounge on the other side have balance pressure. We reported a 60-year-old male patient with chief complaints of difficulty in mastication, and loose upper and lower dentures. He also complained of denture moving during swallowing and speaking. In case management, the aim was to acquire optimum stability of the denture and arrangement of the mandibular teeth in full dental prosthesis guided by using the neutral zone. Preliminary impression was done by using alginate, then, horizontal and vertical jaw relation was recorded by using bite rim. Suction method impression technique was used to acquire functional impression. Lower denture teeth arrangement adapted the result of neutral zone impression. Acrylic denture was being contoured to adjust the natural anatomy of the oral cavity. In conclusion, the patient got a new full denture with maximum retention and stability while speaking as well as masticating. This article discussed about making of full dental prosthesis with pressure point on neutral zone impression technique on flat mandibular ridge caused by huge resorption.
\end{abstract}

Keywords: flat mandibular ridge; denture stability; neutral zone; impression technique

\section{INTRODUCTION}

Missing teeth can result in multifactorial changes inside the mouth, inter alia alveolar ridge resorption, tongue expansion, and weakening of face muscles. Resorption of mandibular ridge occurs from the lingual plate allowing for more space for tongue movement leading to tongue enlargement over the years. On the contrary, the cheek and lip muscles will lose their tonicity with the advancing age. ${ }^{1}$

The relationship of denture base to surface tissue is an important factor in maintaining stability. Certain biological and mechanical properties provide retention, support, and stability to dentures. Retention provides psychological comfort, stability provide physiological comfort, and support provides longevity to the patient; these factors needs to be summated for a successful prosthesis. Denture instability adversely affects support and retention, therefore, it results in deleterious forces on the edentulous ridges during functioning. A denture that shifts easily in response to laterally applied forces can cause a disruption in the border seal or prevent the denture base from correctly relating to the supporting tissues. ${ }^{2}$

Sir Wilfred Fish explained that there were three surfaces of denture that affect stability and retention, as follows: 1) Impression surface: part of denture that make soft contact with tissue below the denture. Retention was acquired from attachment strength, that was adhesive and atmospheric pressure; 2) Occlusal surface: area that made contact with teeth, either natural teeth or denture elements. Strength coming from 
masticatory muscles immediately was received by occlusal surface. Denture stability during occlusion was determined by impression surface with soft tissue and occlusal surface and other factors; 3) Polished surface: denture surface that made contact with buccal, lingual, and labial mucosa, were also important for stability and retention of dental prosthesis. $^{3}$

Neutral zone is an important phenomenon; therefore, it is essential to recognize the importance of neutral zone in teeth arrangement and polished surface which gives stability. ${ }^{2}$ The neutral zone is a potential area where forces generated in an outward direction from the tongue are being neutralized or balanced by the inward forces generated by lips and cheeks during functional activities. ${ }^{4}$

In determining the neutral zone on posterior teeth, there are no teeth that can be used as a guidance in detecting the exact location of the neutral zone. However, as clinicians, we can detect the exact location of a neutral zone by letting the muscles themselves to create a neutral zone impression on impression compound during swallowing process. Observation on several neutral zone impressions which had been seen first are the width consistency that we get from the neutral zone, and it will become the guidance that is connected to determine the normal teeth width. This also describes that inside the mouth that has lost its posterior teeth for a long time, outward tounge pressure is still being balanced by inward buccinator muscle pressure that is strong enough to position the neutral zone within the normal conformity on edentulous ridge. ${ }^{5}$

Determining neutral zone on anterior teeth is by defining the functional relation between tounge and perioral muscles. A phonetic method with high accuration can be used because the sound is produced from precise approximation of upper and lower teeth with lips and tounge. Contact near structures that cause the narrowing of air flow to form certain sound, also can be used as guidance in determining incisal edge position and entire incisal plain. The lips' path of closure can be used to determine labial contour and the anterior guidance method can be used to determine palatal contour. When all functional relationships are correct, teeth will be in sync with neutral zone. ${ }^{5}$

In patient with mandibular ridge resorption, the retention of using dental implant become a contraindication if the patient has systemic disease history, such as diabetes mellitus, osteoporosis, or on radiotherapy treatment. Conventional denture can be used as an alternative treatment. ${ }^{6}$ Therefore, to acquire a denture with good stability and retention, the procedure of functional impression and obtaining a good and right neutral zone should be considered. ${ }^{4}$ This present article describes a novel method to gain maximum retention, stability, and masticatory efficiency in cases of severely resorbed ridges with neutral zone technique by simple usage of materials available by the dental chairside assistant.

\section{CASE REPORT}

A 60-year-old male patient reported to the Department of Prosthodontics, Airlangga University, with chief complaints of difficulty in mastication, loose upper and lower dentures, and poor esthetics. He also complained of denture moving during swallowing and speaking. Clinical examination revealed that the patient had no gross facial asymmetry. The temporomandibular joint (TMJ), muscles of mastication and facial expression were asymptomatic. No gross abnormalities were detected in the overall soft tissues of the lips, cheeks, tongue, and oral mucosa (Figure 1).

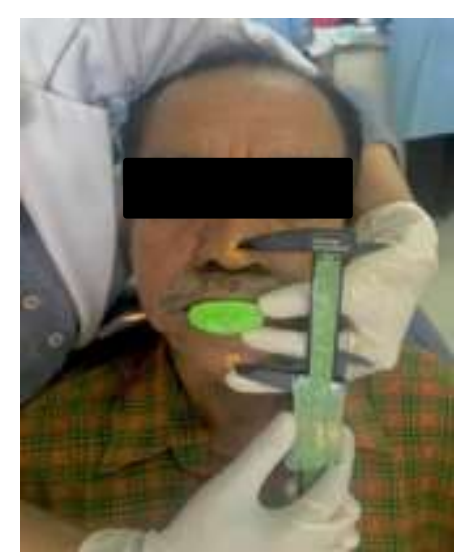

Figure 1. Impression using centic tray 
In intraoral examination, flat (atrophic) mandibular ridge type III according to American College of Prosthodontic was detected (Figure 2). There was no hypermobile tissue on palpation. The objective of the treatment was to rehabilitate the patient with a complete denture therapy by locating the neutral zone and accordingly arrange the denture teeth and contour, the complete denture polished surface, as well as maximum prosthesis stability, comfort, and function.

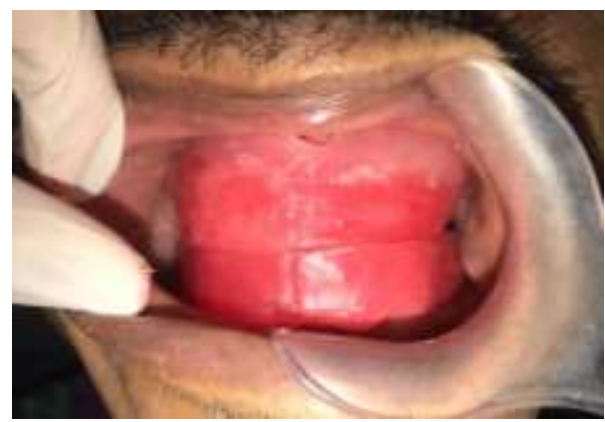

Figure 2. Bite rim try in

\section{Treatment Procedure}

The primary impressions of maxillary and mandibular denture bearing area were made with irreversible hydrocolloid impression material. For mandibular ridge, impres- sion was made with frame cut back (FCB) tray. As soon as primary impression was made, the impression was poured in plaster. Then, the impression was made with centric tray to determine vertical dimension and bite position on the patient (Figure 1).

Mounting of the primary model on average value articulator using the impression was done on a centric tray. Bite rim was being manipulated according to vertical relation that was acquired before, and being prepared to make functional impression using closed mouth technique (Figure 2).

In closed mouth impression technique, pillars on canine and molar area of mandibular bite rim were made (Figure 3)

In closed mouth technique, the first thing that needed to be done was border mould using monophase. Patient was instructed to move masticatory muscle by pronouncing letter "U" and "E", and then for maxilla, patient was instructed to say "AHA" loudly and followed by swallowing movement. On mandibule, impression was being done by sticking the tongue out forward and to left and right, followed by sucking movement and swallowing saliva (Figure 4).

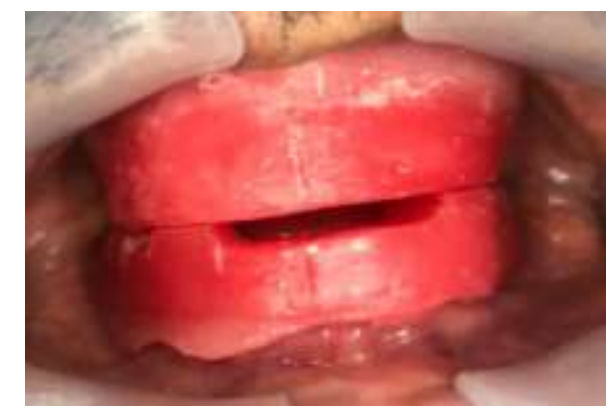

Figure 3. Making pillars on mandibular bite rim

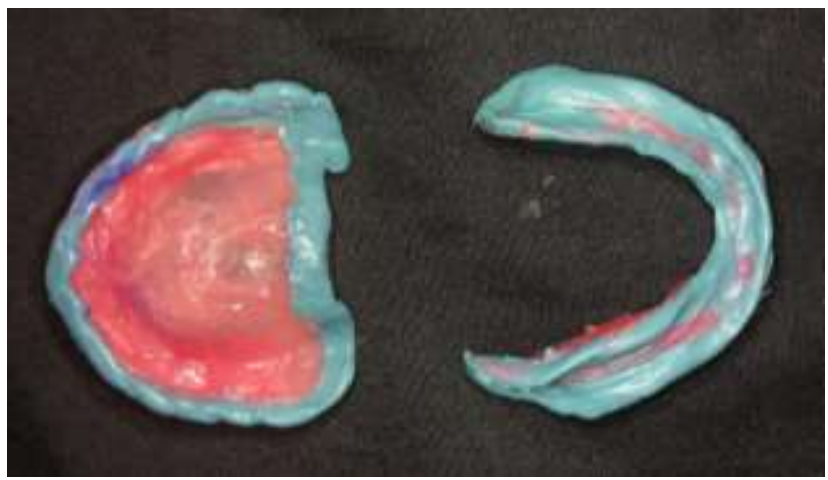

Figure 4. Border molding on closed mouth technique 
After finishing border mould, second impression was being done using light body. Functional movement was the same with the border moulding stage. Impression is said to be good if BTC point has already been impressed (Figure 5).

Fixation was done by using polyvinyl siloaxane bite registration. Then, both bite rims were removed together from the patient's mouth (Figure 6).

The next impression was neutral zone impression. Compound wax was manipulated on mandibular ridge with vertical dimension that had already been determined in articulator. The wax was softened by using $60^{\circ} \mathrm{C}$ water bath and was inserted carefully into patient's mouth. The patient was instructed to suck warm water using a straw and then to swallow it, Lips movement was like slurping water. The step was repeated until neutral zone was well impressed (Figure 7).

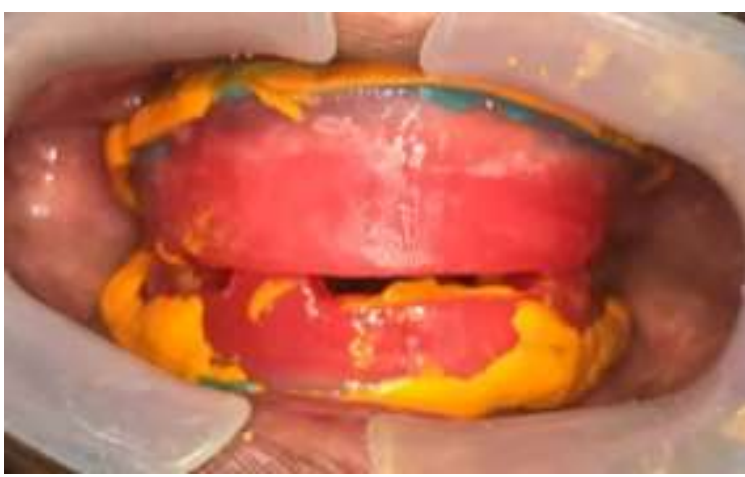

Figure 5. Closed mouth impression
After that, a neutral zone index was used using putty. The putty was manipulated in such a way as in the labial, buccal and lingual areas, then it was matched in the actual bite rim, to guide the arrangement of the teeth (Figure 8).

Tooth arrangement started from the anterior mandible and then was checked with the putty index. Arrangement of the maxillary teeth had to be adjusted with the patient's profile and lips. Then, a denture was processed by using acrylic, polished, inserted, and then checked for its stability and retention (Figure 9).

In follow-up, the patient controls were performed at $1 \times 24$ hours post denture insertion, then day 3 and day 7 . The patient was satisfied because the denture was not shaking and fit well when talking or chewing food.

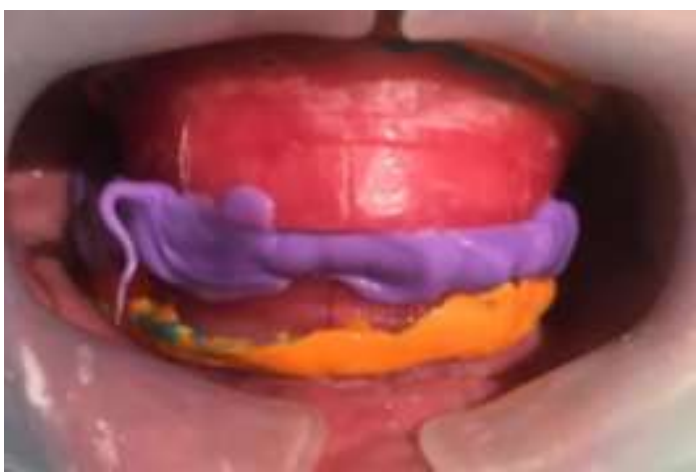

Figure 6. Record bite position using polyvinyl siloxane
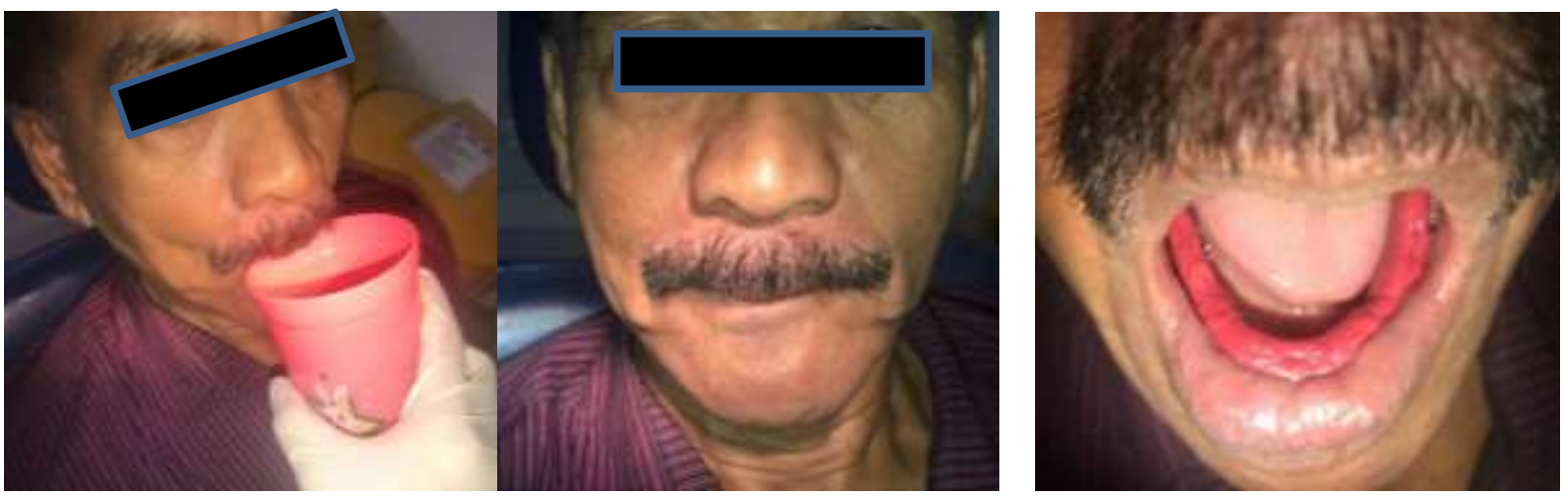

Figure 7. Neutral zone impression steps 

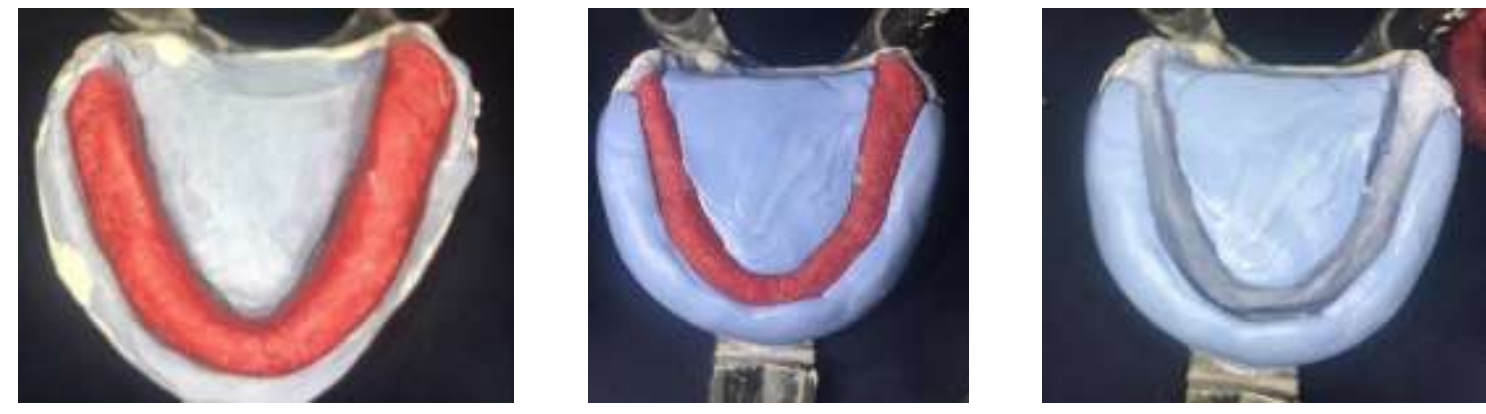

Figure 8. Putty index made after impression of neutral zone
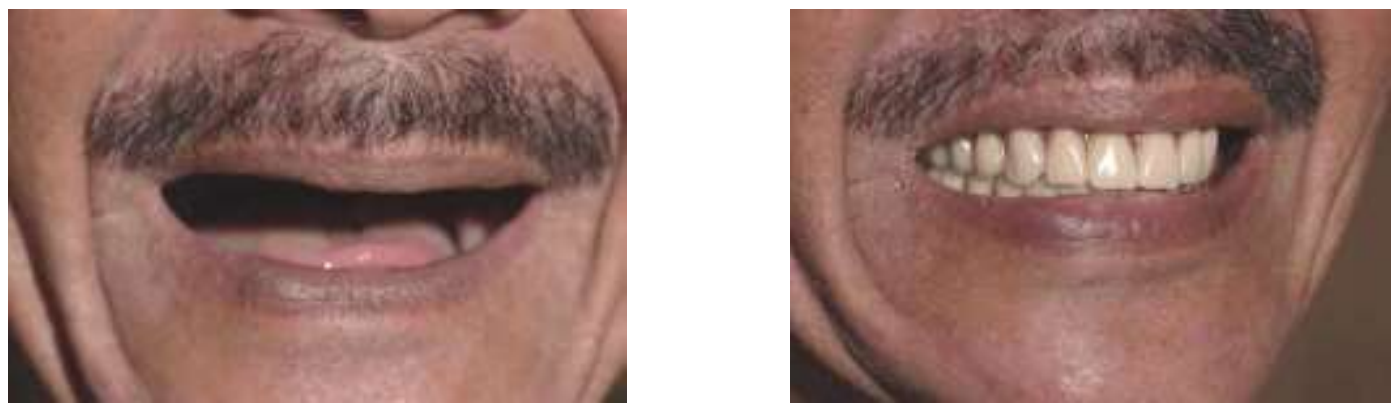

Figure 9. Before and after denture insertion

\section{DISCUSSION}

The ultimate goal of any prosthodontic treatment is to restore the form, function, and aesthetics of the patient. Simple impression procedures have been followed to get the maximum retention and stability of the complete denture, especially on the mandibular ridges. ${ }^{4}$ Providing stable mandibular dentures for patients with severely resorbed mandibular ridges is a challenge. One can overcome this problem if dentures are fabricated with their contours harmonizing neutral zone. The neutral zone is the potential space between the lips and cheeks on one side and the tongue on the other. It is the area where the forces between the tongue and cheeks or lips are equal. When the residual alveolar ridges have resorbed significantly, denture stability and retention are more dependent on the correct position of teeth and contour of the external surfaces of dentures. ${ }^{7}$

Arranging artificial teeth within the neutral zone achieves two important objectives: (1) prosthetic teeth do not interfere with normal muscle function; and (2) normal oral and perioral muscle activity imparts force against the complete dentures that serves to stabilize and retain the prosthesis rather than cause denture displacement. The neutral zone technique typically locates posterior denture teeth slightly facially, when compared to teeth arranged over the crest of the residual alveolar ridge. ${ }^{4}$

\section{Conflict of Interest}

There is no conflict of interest in this study. This study did not receive any financial support and donation

\section{CONCLUSION}

The neutral zone technique helps to achieve a muscular control which will be the main stabilizing and retentive factor during functioning on denture. The success of the denture prosthesis is determined by the exact diagnosis, determination of treatment plan, material selection, determination of denture retention and technique in processing the denture prosthesis.

\section{REFERENCES}

1. Asnani P, Chandu GS, Mishra SK. Neutral zone technique in complete denture - case 
report. J Appl Dent Med Sci. 2015; 1(1):15-8.

2. Mistry R, Pisulkar SK, Bhoyar A, Surekha B, Mandhane R. Stability in complete dentures : an overview. J Dent Med Sci. 2018;17(11):36-41.

3. Zarb G, Hobkirk J, Eckert S, Jacob R. In: Zarb G, editor. Prosthodontic Treatment for Edentulous Patients. St.Louis Missouri: Elesevier Mosby, 2013; p. 421.

4. Mageshwari M, Shetty K, Rahul GR, Hegde D. Neutral zone concept for severely resorbed ridges - a clinical report. Int J Pharm Med Res. 2017; 5(2):438-44.

5. Dawson PE. Functional Occlusion from TMJ to Smile Design (1st ed). Mosby, 2006; p.
648. eBook ISBN: 9780323078986

6. Gómez-de Diego R, Mang-de la Rosa M del R, Romero-Pérez MJ, Cutando-Soriano A, López-Valverde-Centeno A. Indications and contraindications of dental implants in medically compromised patients: update. Med Oral Patol Oral Cir Bucal. 2014;19(5):e483-9.

7. Rowley AJ, Collins J. Management of severly resorbed mandibular ridge using neutral zone technique - a case report. Int $\mathbf{J}$ Recent Sci Res [Internet]. 2015;6(11): 7469-71. Available from: http://www. sciencedirect.com/science/article/pii/S1 521689610000455 